\title{
ON THE LOGIC OF PRAXIOLOGICAL PARADIGMS
}

\author{
Emil, Dinga ${ }^{1}$ \\ Romanian Academy, emildinga2004@gmail.com
}

\begin{abstract}
The paper aims to provide a brief discussion regarding the concept and typology of paradigm, as it is used in the philosophy of science. To this end, a set of sufficiency predicates are proposed that characterize any generic paradigm, based on which a typology of possible categorial paradigms is built up. The category of praxiological paradigm is then logically and historically examined using a logical "filter" with five parameters, including the sustainable paradigm (as barely sprouted today) and the viability paradigm (the most desirable one o be got). The study is carried out from the conceptual and philosophical perspective only.
\end{abstract}

KEY WORDS: paradigm, sustainability, viability, homo significans, praxiology

\section{PREAMBLE}

The human action is, generally, of three kinds: a) theoretical focused on relationships among objects (e.g. scientific activity in natural sciences field); b) praxiological - focused on relationships between subject and object (e.g. economic activity); c) practical - focused on relationships among subjects (e.g. political activity or religious one). Obviously, this typology is rather of academic relevance, since, in fact, the three actions are inter-related or can pass from one to another. Moreover, the most human activities imply two or even all three of the mentioned types of action (e.g. economic activity is increasingly based on natural science, so implies object object relationships, through technical technology, and implies also subject - subject relationships, through management). Nonetheless, for our purpose, is relevant here especially the praxiological type of human activity.

As said, the prototype of the concept of praxiology is the economic activity. By economic activity must be understood, essentially, that human action exerted on the non-anthropic environment which is aimed at to exchange entropy (here, the concept of entropy is that from Thermodynamics - i.e. the degree of homogenization of the structure of a system. Further, as the study goes on, the concept of entropy will be specified more) between human beings and the non-anthropic environment. Such entropic exchange is aimed to maintain human beings alive by meeting their biological needs (primarily by assuring their physical survival - regardless the sophistication (most of time, without a moral justification) of human needs (at least of those objectified as such), the last and the most fundamental need of humans is the need to survive and reproduce. Even in a so abstract activity as the finance one, recent works highlight on surviving/evolutionary models of action [1]. An activity could imply the entropic exchange as a last instance purpose, not as a primary or even of a "visible" intermediate one (e.g. speculative financial activity), but, if such a last instance can be identified (and proved as such) that activity is, without doubt, of economic sort (such a definition of the economic activity is, obviously, incommensurable with the neoclassical definition - enacted by Lionel Robbins and perpetuated until recently - according to which economics (and, so, the economy in itself) must be understood under the aegis of allocation of scarce resources having alternative uses. As it is easy to notice, the opportunity cost implied by
Robbins-ian definition can be used to show that replacing a football player with another is an...economic decision (among others, Nobel laureate Gary Becker did not have any emotion to do this step). Such a defining of the economic "animal" (or, better said, of the predicate of economic) provide some epistemological and praxiological consequences, as follows:

-economic activity exists regardless the resources involved are or are not scarce;

-economic activity exists regardless the resources involved have or have not alternative uses;

-economic activity does not imply at all the cooperation among subjects (cooperation constraint comes from the reasons of efficiency (or, sometimes, of efficacy), but not from the definitional reason) - even a single subject (i.e. an individual) can practice economic activity if its purpose is the (of last instance) entropic exchange with the non-anthropic environment;

-no matter how far away the entropic exchange is, its identification is imperative to be established if it is speaking about economic or about something else (from semantic (or, more general, semiotic) perspective, an economic statement must allow such an identification of the last instance purpose of entropic exchange, otherwise that statement is not of economic nature. Of course, here we have a spring for some epistemological discussions regarding the economic process. In the final chapters of the book, brief considerations in this field will be delivered).

A problem is arising here: what about the non-human animals (or even what about plants or other entities) which seem make entropic exchange with their environment (this time either non-anthropic or anthropic)? My answer is the following: although the entropic exchange is the last instance mark of the economic, this predicate must concomitantly verify other four sufficient attributes:

-to be of ontological sort: this means the economic must objectively (any economic (or, more general, social) entity, process, phenomenon, or event are only outcomes of human being action. They do not appear, do not function, and do not disappear than if and only if the human action is implied (either directly or indirectly). All economic factuals are caused by human being (or, usually, by human beings' cooperation inside the social game). However, the economic is still of objective 
nature - the so-called third Popper-ian world, that is, the objectifying of the inter-subjectivity) exist (e.g. Heisenberg's imprecision in Quantum Mechanics is not of economic nature, because it belongs to epistemological realm);

-to involve the choice: this means the economic must operate through choices made on the resources (e.g. the movement of light on space-time geodesic is not "something" economic, although it is an aspect of existence, that is, it is of ontological sort);

- to be based on a purpose: this means the economic (both as predicate and action) must stay under an a priori purpose which must be accomplished (e.g. the marriage is not of economic nature, although it belongs to ontology and implies a choice).

So, based on an additional assumption that the human beings only are able to have purposes in a conscious way (the apparent purposes of animals, in their struggle for existence, should be considered (at least in the current scientific light) of instinctive sort. Although it seems much of human behaviour impulses are located within the unconsciousness, only the only conscious thoughts lead to economic actions (either acts or abstentions). For behavioural analyses in the economic field, see the works of Kahneman, Thaler, Mlodinow, Gigerenzer, among others), animals (or other non-human entities which hold the mark of entropic exchange) do not perform economic activity.

\section{CONCEPT OF PRAXIOLOGICAL PARADIGM}

Originated in Greek terminology ( $\pi \alpha \rho \alpha ́ \delta \varepsilon \imath \gamma \mu \alpha$ parádeigma, from $\pi \alpha \rho \alpha ́$ pará, meaning "next" or "to" and $\delta$ cíkvoul deíknymi, meaning "show" or "make understandable"), the concept of paradigm means model, pattern, way of thinking or of action. The most known use of the concept is that of cognitive (more precisely, scientific knowledge) paradigm introduced by [2]. I do not discuss here this cognitive concept but the general traits of it will be adapted to examine the concept of praxiological paradigm. To be at the outset that, while the Kuhn-ian paradigm addresses the theoretical activity (object-object relationships), the praxiological one addresses the praxiological activity (subjectobject relationships).

\subsection{A logical introducing of the concept of paradigm}

Generally, a paradigm is a model of rationality, regardless its purpose (cognitive, practical or praxiological) - a question could be put here: in the animal realm, when hunt, some species act in the pack (for example, the wolves), while other species acts individually (for example, cheetahs). Really, the two species have they simply different models of rationality? Again we must appeal the anchor of consciousness: we can speak about models of rationality only when such models are conscious. In the case of animals, the instinct, adapted to the environment led to some specific models of behaviour, but not to models of rationality. The finality is more general than the purpose - the purpose ist he conscious finality. I consider that a paradigm, in the most abstract way, has a structure based on four components:

(1)value (V): the value addresses the founding of the paradigm's finality. For example, the selfishness is the value of paradigm of homo œconomicus;

(2)nucleus $(\mathrm{N})$ : the nucleus addresses the prime (primitive, fundamental) principle of paradigm, which is "responsible" for the behaviour. For example, the complete rationality, in the case of paradigm of homo œconomicus;

(3)function (F): the function addresses the finality of paradigm (in fact, the purpose of actors using that paradigm). For example, the minimizing of the opportunity in the case of paradigm of homo œconomicus;

(4) logic (L): the logic addresses the principles of rationalization (rationalization is a justification based on a model of rationality. Although, principled, rationalization occurs before decision and action (by a valid inferring of that decision from the model of rationality concerned), behavioural psychology has showed that, frequently enough, the rationalization occurs after the decision is taken or the action is performed) of paradigm. For example, the methodological individualism in the case of paradigm of homo œconomicus.

Figure 1 describes the general structure and functioning of an abstract paradigm.

The value of paradigm generates its nucleus, which, in turn, generates its function, which, finally, built up its logic.

Validating the paradigm conserves its justification, which, in turn, verifies its explanation, which, finally, could falsify (in the Popper-ian sense) its grounding.

The abstract functioning in Figure 1 is valid for any kind of paradigms. In fact, can exist three kinds of paradigms:

(a)for theoretical activity: cognitive (gnoseological) paradigms (the finality is more general than the purpose - the purpose is the conscious finality) - the Kuhn-ian paradigm is of this cognitive type. The cognitive paradigm maintains only two components of the general paradigm): nucleus and logic (so, it is a NL paradigm), because the cognitive paradigm does not need a function (the internal logic of knowledge, for example, does not provide any function - knowledge is something... free) nor does it have to be based on a value (that is, the knowledge must not allow value judgements);

(b)for praxiological activity: praxiological (actional) paradigms (as will be developed further). The praxiological paradigm holds all components from the general paradigm, so it is a complete paradigm (it is a VNFL paradigm);

(c)for practical activity: comprehensive (hermeneutic) paradigms. The comprehensive paradigm holds three of four components of the general paradigm: value, nucleus, and logic (so, it is a VNL paradigm), because the comprehensive paradigm does not need the function (understanding the world and the self are sine qua non commands of the cultural subject).

Figure 2 and 3 synoptically illustrates the cognitive and comprehensive, respectively, kinds of paradigms by using the general (abstract) model in Figure 1

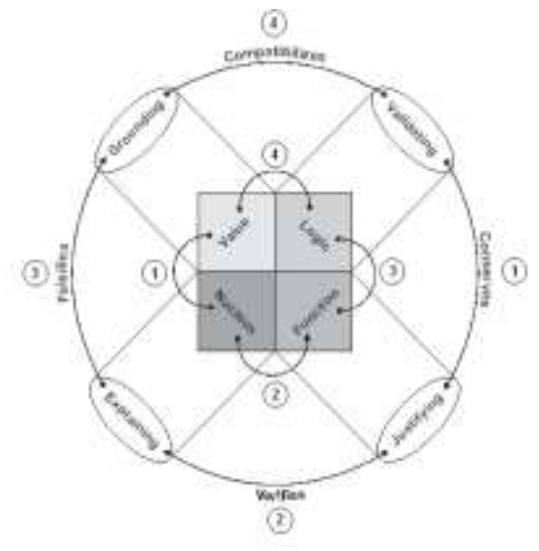


Figure 1. The structure and functioning of the general/praxiological paradigm

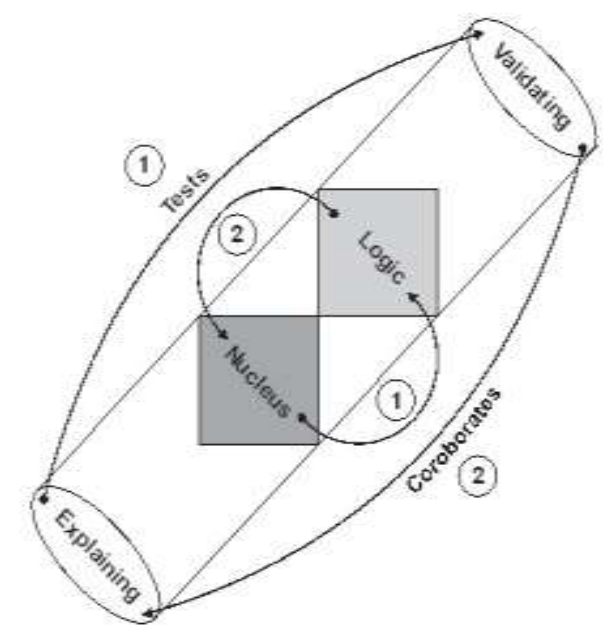

Figure 2. The structure and functioning of the cognitive paradigm

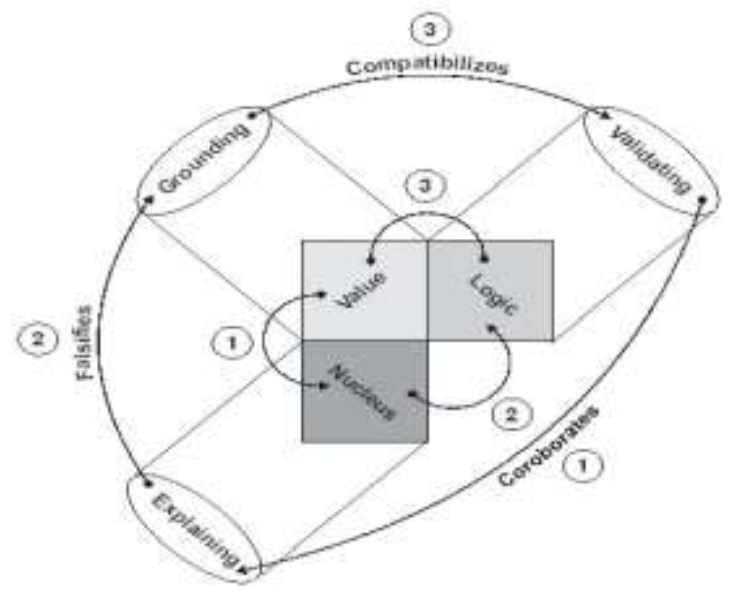

Figure 3. The structure and functioning of the comprehensive paradigm

Relationships between subject and object for every type of paradigm are shown in Figure 4.

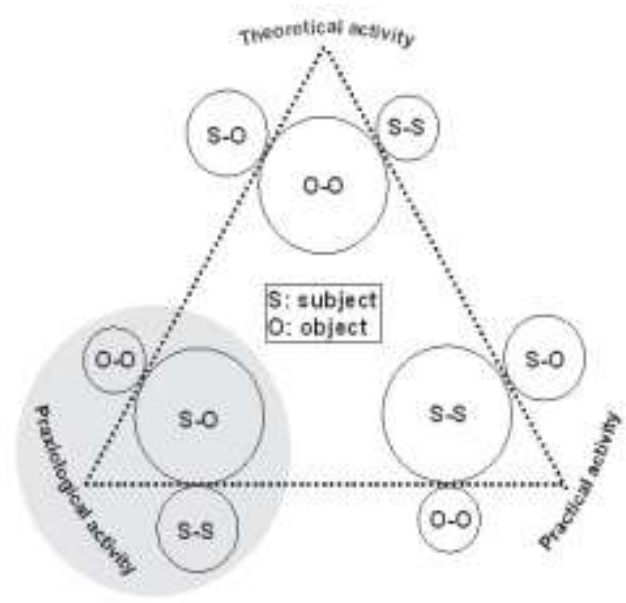

Figure 4. The intensities of relationships subject - object, by type of paradigm

\subsection{Historical view on praxiological paradigms}

Historically, it seems four praxiological paradigms are of interest [3]: a) stationarity paradigm (NP); b) optimality paradigm (OP); c) sustainability paradigm (SP); d) viability paradigm (VP). We shall briefly discuss these paradigms, in the logical framework provided in paragraph 2.1. Before that, some words about the passing mechanism from a paradigm to another are of usefulness.

\subsubsection{On the mechanism of inter-paradigms transition}

The praxiological paradigms are aimed at to reach their own values. When these values become difficult (or impossible) to be met, a process of passing to another paradigm is initiated. This initiation can be either spontaneous within the community concerned - do not forget that any social „object” is always the result of humans' action - or, less often, the effect of a conscious project which usually is triggered by a great personality or a group around such a personality (the ,personal" initiation of a praxiological paradigm changing is rather theoretical, although, sometimes, some seeds announcing the new paradigm can be thrown by personalities - for example, the Fordism which announces the optimality paradigm in industry. Also, social revolutions can light the spark of future (still unclear at the moment) paradigms - for example, the agricultural revolution). Why a paradigm's value might become difficult (or even impossible) to be met. There are some (theoretical) cases:

$\bullet$ economic force (EF):

- ratio available resources - needed resources becomes less than 1. This case can occur from both „sides”: a) from resources side - some non-renewable resources are exhausted or the pace of consumption of renewable resources is bigger, for a long time, than the pace of their recovery; b) from needs side - the humans's needs increases either quantitatively, or structurally, or qualitatively, which requires a change in the economic type of production, distribution, consumption. For example, the inventing of agriculture has been induced by the economic force;

-social force (SF):

- distribution of social positions (which implies social benefits from the cooperation game) become unfair, that is, an implicit social hierarchy based on a dissimulated endowing of power is installing. Although this case seems to be assignable rather to practical paradigms, its role in the praxiological ones are so strong so that we admit it as a spring of interparadigmatical transition. For example, the (proved as false) socialist/communist (intended) paradigm of equality (and of its consequences) has been induced by the social force;

•moral force (MF):

- the sense of life, and the sense of togetherness become problematic, so questionable. The general configuration of society (basic structure, in Rawls terminology [4]) at a given moment, could be considered as incompatible with the moral values or, more precise, the ethical values (we operate a distinction between ethics and morals (following the position of Michel Foucault in the Hermeneutics of the subject. Lectures at the College de France 19811982), namely: ethics is idiosincratic, completely 
subjective, while morals is the (overlapped) commonly accepted, at the social level, of individuals' ethics. This way, morals is, in fact, an objectification of the inter-subjectivities in the ethical territory, representing the externally accepted

Of course, the three (rather academically identified) forces to induce the inter-paradigmatical transition can act in binomial or trinomial configuration in such an induce, depending on the concrete economic, social, and moral context.

\subsubsection{The past and foreseeable praxiological paradigms}

In this paragraph, the four historical praxiological paradigms will be very brief examined, from five perspectives: 1) logical description; 2) the behavioural pattern involved; 3) the dominant force leading to the transition towards next paradigm; 4) social-political regime; 5) the transition mechanism to next paradigm; 6) the current state of the paradigm concerned. (common) core of the different ethics at a moment.), by a critical mass of individuals [5]. For example, the current exponential consumerism, even based on legal gains, seems to take the individual away from its generic human condition.

The historical concatenation of praxiological paradigms describes a "logical" mistake. More exactly, it seems the "correct" next paradigm after the NP should be the SP one, but factually was the OP. Subsequently, history then "adjusted" the mistake, so that after the OP, the humankind returned to the $\mathrm{SP}$, which is a more mature sort of the NP. Figure 5 exposes this path error (qualifying the passing from NP to OP as a "logical" mistake is, of course, a metaphorical way of speaking. Such an evaluation is possible ex post only and, somewhat, only from office. Praxiologically, the human society has experimented various chreods, as biological evolution exhibits, some of them proving (only later) as wrong).

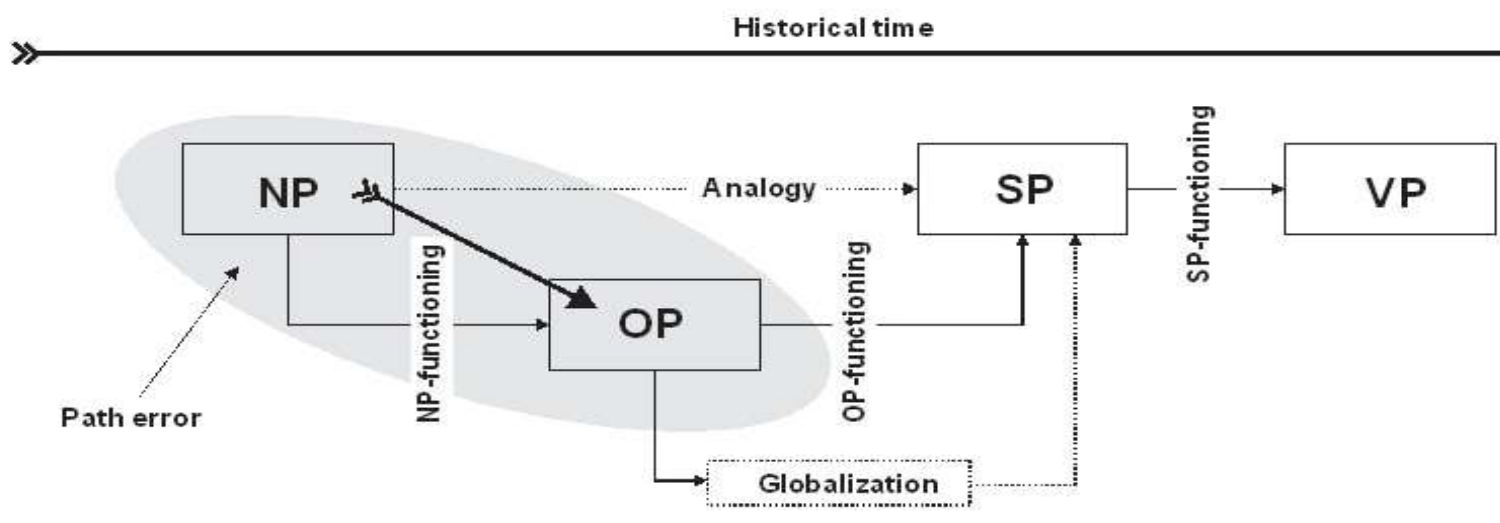

Figure 5. The path error in historical concatenation of praxiological paradigms

\section{(a) Stationarity paradigm (NP)}

\section{(a1) logical description of NP}

This paradigm has functioned before agriculture was been invented, that is, in human communities formed by hunters and gatherers. People survived by seeking food when the starvation pushed them, without ever have surplus of food. The hypostases of the four marks of praxiological paradigm of stationarity are the following:

- value: naturalness - the founding principle of NP is the naturalness, meaning that individuals follow their natural condition, extremely less "contaminated" by cultural one, although, of course, the individuals are social beings and live in (relatively small) communities. One of the efficient causes of the naturalness of NP is, obviously, the lack of sedentarism which would had increased the permanent social relationships weight;

- nucleus: heuristics - the primary principle of NP is heuristics. Individuals under this paradigm behaviour in the most cases by ,trying and error" and learn thus way. Although learning by ,trying and error" has the potential to lead (with an extremely small speed, however) to some patterns of behaviour, the quantity and quality of such a transition to learnt patterns is quite poor;
- function: a-moral survival - finality of NP is the biological (and a-moral) survival, including the biological reproduction. The most part of survival, and, implicitly, of species' reproduction, is driven by natural selection, that is, by the natural driver;

- logic: biological methodology - the massively dominant type of rationalization (or justification) within NP is that biological. Individuals evaluate, developed and „approve" those behaviour, results, and social structures which seem to serve for biological purposes;

(a2) the behavioural pattern of NP: homo naturalis;

(a3) the dominant force of transition towards OP: economic force;

(a4) social-political regime: autarchy;

(a5) transition mechanism towards OP:

The transition mechanism from NP to optimal paradigm OP is generated by worsening of the ratio resources - needs, because the rapid increasing of population (without technological and social innovation, the future Malthus's theory is fully verified in NP, avant la lettre), which generated a competition for resources. The crucial solution to this problem was an invention which led to an exponentially increase of the resources - agriculture (there are scholars who believe that, by the contrary, invention of agriculture constituted a mistake in the humankind history (see, for example, Yuval Noah Harari's 
Sapiens: a Brief History of Humankind), but such debates are outside of the chapter's interest.) [6];

(a6) the current state of NP: overfulfilled (except, probably some small and isolated groups).

\section{(b)Optimality paradigm (OP)}

\section{(b1) logical description of OP}

- value: selfishness - the founding principle of $\mathrm{OP}$ is selfishness, because, after triggering of the competition for resources (in NP era), this competition easily passed into the competition among individuals, both for resources and for social positions (i.e. for power). To be noticed that, also in NP the selfishness was in place, but until the ratio resources - needs has not become less that 1 , it was not required to be objectified. Consequently, OP did not coin the selfishness (which seems to have been put in the "hardware" of the human nature and kept as such in the human condition too), but explicitly and generally put it at the basis of social cooperation game;

- nucleus: hyper-rationality - the primary principle of OP is the complete rationality. The concept of rationality in $\mathrm{OP}$ is based in the neoclassical economic theory, with its axioms (David Colander has provided the axioms which seems to drive the neoclassical economic theory: a) focusing on allocation of resources at a given moment in time; b) accepting some variation of utilitarianism as playing a central role in understanding the economy; c) focusing on marginal trade-offs; d) assuming farsighted rationality; e) accepting methodological individualism; f) being structured around a general equilibrium conception of the economy) [7]. Although there are many essays to relax one or more of Colander's axioms (including the famous concept of bounded rationality of Herbert Simon, that he introduced in 1957, in his work Models of Man, New York: John Wiley), in essence OP stays based on the neoclassical economic theory;

- function: a-moral extremization (extremization is of two sorts - minimization or maximization. Either one or other of them means to get the extreme value of an established function-goal subjected to an established set of constraints. That is, that extreme value is relativized to the set of constraints, it has not an absolute character - Nota bene: similarly with the rationality that is as such only subjected to a model of rationality, not absolutely) - finality of $\mathrm{OP}$ is to minimize the opportunity cost of economic decision, which is equivalent with getting the extreme value (either maximum or minimum, after the economic variable concerned) of a function-goal subjected to a set of constraints (restrictions). This extremization is a-moral, because no moral constraints are introduced in the process of extremizing. The (economic) preferences which are considered regarding individual's choice making are not of a moral nature, but are rational expectations or beliefs;

- logic: individualistic methodology - the massively dominant type of rationalization (or justification) within OP is linked to individuals, so that the macrobehaviour is considered an integration ("sum") of micro-behaviours (including the synergy generated just by the integration of micro-systems into a macrosystem); (b2) the behavioural pattern of OP: homo øeconomicus;

(b3) the dominant force of transition towards SP: social force;

(b4) social-political regime: capitalism;

(b5) transition mechanism towards SP:

The transition mechanism from OP to optimal paradigm SP is generated by its very function - extremization (for example, profit maximization). To get such a result, OP must exploit resources-niches across the world, which generates the wellknown process of globalization. The globalization as it is practiced today (it is easy to prove that the current globalization type is similar with a Ponzi scheme: the more of new niches of (cheap) resources are got the less marginal profit are made (such a result is obviously analogous with at least two results obtained in economic theory: a) a result from the political economy realm -Marx's theory regarding the decreasing of the profit rate in the capitalism; b) a result from the neoclassical economics - Fama's Efficient Market Hypothesis). Both results say: by exploiting opportunities which bring advantages above the market average (at the same risk assuming and cost paid) the opportunities concerned disappear) will turn exactly against OP, because the OP's function acts as a positive feed-back that necessarily lead to eliminating all sources of achieving that function;

(b6) the current state of OP: fully working across the world.

(c)Sustainability paradigm (SP)

(c1) logical description of OP

- value: togetherness - founding principle of SP is the "common boat" principle, which means that the way in which the life is ensured affect all people, regardless physical or social boundaries. That is, each of us can contribute to the social good or, conversely, each of us can contribute to the social mal. This togetherness is aimed at to move the humanity towards a new attitude related to our environment physical/non-anthropical, anthropical/social, mental and others likewise;

- nucleus: autopoiesis - the primary principle of SP is of evolutionary type, but on a mixed kind of evolution, which combine the natural/biological evolution with the cultural/social one (it seems to me that the diad nature-nurture, that is, (introduced in literature by Francis Galton in his works Hereditary Genius, in 1869, and English Men of Science: Nature and Nurture, in 1874) should be completed to a triad, namely nature-nurture-culture, although, at limit, the culture can, however, be considered to belonging to nurture). The concept of autopoiesis integrates the inherent evolution with its "assurance" provided by the awareness of long term (at limit, of indefinite term) which the humankind existence must be based on;

- function: a-moral stable replicability - finality of SP is to meet the principles, normative framework, and social organizations so that the society (with its important economic realm) (at least) be stably replicated and, if possible, stably be improved. Like the two previous praxiological paradigms, SP's replication (and replicability) is a-morally grounded, it having to provide only the stability of that replication;

- logic: communitarian methodology - the massively dominant type of rationalization (or justification) within SP is a communitarian methodology. As the 
SP's value requires, the sustainable societal system must be profitable to the entire society, not to individuals (as OP proceeds). So, the individualistic methodology (as logic of OP) must be replaced by a communitarian one;

(c2) the behavioural pattern of SP: homo socionomicus. This behavioural pattern biases from the homo economicus behavioural pattern precisely by replacing the individualistic methodology with the communitarian one;

(c3) the dominant force of transition towards VP: moral force;

(c4) social-political regime: communitarianism;

(c5) transition mechanism towards VP:

The transition mechanism from SP VP is generated by SP's very function - replicable stability. To get such a result, the replications must be massively, strongly, continuously, and permanently supported by the people. This means, people must see their ethical (and, correspondingly, moral) values be respected, promoted, and defended. Such properties of the societal system can be only delivered by VP, which, for first time, includes the moral values in the societal dynamics. Consequently, the transition mechanism consists in gradually but firmly introducing of moral bases in basic structure of society. Thus, a moral-based sustainability will pass into viability;

(c6) the current state of SP: at the beginning (some timid and isolated attempts to establish the sustainability paradigm, are occurring, for now, in the very framework of dominant OP).

(d) Viability paradigm (VP)

\section{REFERENCES}

[1] A. Lo, Adaptive Markets (2019).

[2] T. S. Kuhn, By Thomas S. Kuhn - The Structure of Scientific Revolutions: 50th Anniversary Edition. University of Chicago Press (2012).

[3] E. Dinga, Rebuilding Economics: A Logical, Epistemological and Methodological Approach. LAP LAMBERT Academic Publishing, (2012). (d1) logical description of VP

- value: spiritualness - the founding principle of VP represents a return from sociality to individuality, after the society already gained its (communitarian) sustainable property. The spiritualness re-meets, after an entire history of humankind, the individual in its most proper predicates;

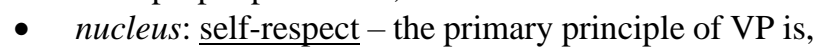
this time, the self-respect (the self-respect is a more fundamental value than freedom one (and history proved this many times), because freedom can be validly inferred from self-respect, but not conversely - like democracy can be validly inferred from freedom, but not conversely);

- function: moral stable replicability- finality of VP is the same as in SP, with the significant distinction that the stable replicability of the society as a whole must be achieved from a moral perspective or based on moral values;

- logic: holistic methodology - the massively dominant type of rationalization (or justification) within VP is of holistic type, namely based on the principle: the entire drive the parts;

(d2) the behavioural pattern of SP: homo significans;

(d3) the dominant force of transition towards ?: Not the case;

(d4) social-political regime: humanism;

(d5) transition mechanism towards ?: it is expected this praxiological paradigm be permanentized;

(d6) the current state of VP: desirable

[4] J. Rawls, A THEORY OF JUSTICE, Cambridge, Massachusetts: The Belknap Press of Harvard University Press, (1999).

[5] M. Foucault, A. I. Davidson, F. Ewald, and A. Fontana, The Hermeneutics of the Subject: Lectures at the Collège de France 1981--1982, New York: Picador, (2005).

[6] Y. N. Harari, Sapiens: A Brief History of Humankind, New York: Harper, (2015).

[7] D. Colander, 'The Death of Neoclassical Economics', Journal of the History of Economic Thought, vol. 22, no. 2, pp. 127-143, Jun. 2000, doi: 10.1080/10427710050025330. 